Case Report

\title{
Cefixime and Ofloxacin fixed dose combination induced petechial rash: a case report
}

\author{
Sudhir Kumar ${ }^{1} *$, Kirti Nirmal ${ }^{2}$, Amit Kumar Nirmal ${ }^{3}$, S. K. Bhattacharya ${ }^{1}$
}

\begin{abstract}
${ }^{1}$ Department of Pharmacology, Hindu Roa Hospital and Medical Collage, North Delhi Muncipal Corporation, Malka Ganj, New Delhi 110007, India ${ }^{2}$ Department of Microbiology, University College of Medical Sciences and Guru Tag Bahadur Hospital, East Delhi 110095 , India

${ }^{3}$ Department of Pathology, Saraswathi Institute of Medical Sciences, Hapur, Uttar Prdesh, India
\end{abstract}

Received: 18 October 2016 Accepted: 17 November 2016

\section{*Correspondence to: \\ Dr. Sudhir Kumar, \\ Email: \\ dr.sudhir2009@gmail.com}

Copyright: () the author(s), publisher and licensee Medip Academy. This is an openaccess article distributed under the terms of the Creative Commons Attribution NonCommercial License, which permits unrestricted noncommercial use, distribution, and reproduction in any medium, provided the original work is properly cited.

\begin{abstract}
Petechial rash is a type of rash which is associated with many infectious and non-infectious conditions. We present a case of Petechial rash induced by administration of cefixime with ofloxacin tablet. A eighteen year old male patient reported to us with a presentation of rash with itching for three days on administration of the fixed dose combination of cefixime + ofloxacin along with paracetamol for the previous symptoms of fever with chills, headache and bodyache. Patient describes itching in the rash which is increasing. The duty doctor attended the patient and immediately stopped the further administration of the offending medication. The patient was prescribed tablet cetirizine orally along with calamine lotion for local application. The patient reported back in for follow-up and was without any residual rashes or other such complaints. He was advised to remember and cautious from the use of drugs in the offending category.
\end{abstract}

Keywords: Cefixime, Fever, Petechial rash, Ofloxacin

\section{INTRODUCTION}

Petechial rash is a type of rash which is associated with many infectious and non-infectious conditions petechial rash is due to chronic sun exposure, glucocorticoid therapy, trauma, anticoagulants, inflammatory disorders on the lower extremities or other dependent sites, arthropod bites, scurvy, platelet deficiencies or dysfunction, cholesterol emboli, septic emboli, systemic amyloidosis, strongyloidiasis, purpura fulminans, livedoid vasculopathy, and hypercoagulable and thrombotic disorders. ${ }^{1}$ Cefixime and ofloxacin are common drugs used in many infectious conditions. Combinations of the drugs show good bacterial spectrum. Adverse effect profile of both drugs is mild to moderate. Stool change and diarrhoea are most common side effect for cefixime. The most common adverse reactions involve the gastrointestinal tract, with $3-17 \%$ of patients 
reporting mostly mild nausea, vomiting, and/or abdominal discomfort with ofloxacin. Rashes on the palm and planter surfaces of foot with these two drugs are not common. In this report, the rashes on palm and planter surfaces of foot due to administration of combination of cefixime and ofloxacin give a new sight of precaution before administration of these drugs in combination and fixed drug combination (FDC). The patient had given consent to be participated in this study and ethical (IEC) approved also.

\section{METHODS}

An 18 year boy came to our tertiary hospital in medicine OPD with the complaint of fever which was continuous in nature along with chills, throbbing headache, body ache and anorexia for last 3 days. No history of cough cold, body rashes, joint pain bleeding from any obvious sites. On examination temp was $103^{\circ} \mathrm{f}$ and pulse rate was $95 / \mathrm{min}$. blood pressure was $132 / 84 \mathrm{~mm}$ of $\mathrm{Hg}$ and heart rate was $40 \mathrm{bpm}$. He was prescribed Tab Paracetamol 650 $\mathrm{mg}$ thrice a day with Tab Ranitidine $150 \mathrm{mg}$ thrice a day and syrup multivitamin 1 teaspoon (TSF) thrice a day for one week. His biochemical investigation on day 1 was Hemoglobin- $14.2 \mathrm{gm} / \mathrm{dl}$, Total leucocyte count$4.3 \times 10^{3} / \mathrm{MicroL}$, Differential Leucocyte Count $70 / 22 / 05 / 03 /$ cumm. and other blood parameter was PCV39.1, MCV- 92.4 fantoLitre, MCH-35.2pg, and platelet count-1.40 lakh/cumm. On day 2, Peripheral smear for Malaria parasite was negative. NS1 antigen detection by rapid diagnostic kit (SD-BIOLINE) was also done for dengue infection which was non-reactive. Chikungunya serology for IgM/ IgG antibody was also negative.

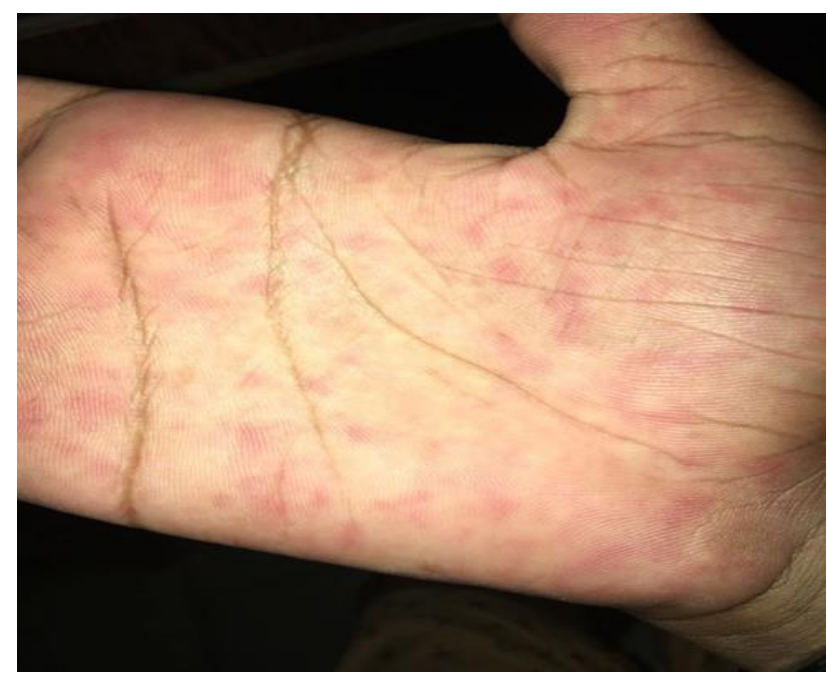

Figure 1: Petechial on palmer surface on hand on day 5 of medication.

On Day 3 patients developed mild joint pain in the body and fever was still persisting approx. $100^{\circ} \mathrm{f}$. Investigation on Day 3 - (TLC-3, $1 \times 10^{3} /$ MicroL, Platelet count -1.39 lakh/cumm) and he was prescribed a fixed dose combination of (Cefixime $250 \mathrm{mg}+$ Ofloxacin $200 \mathrm{mg}$ ) twice a day for 3 days along with Tab Paracetamol 650 mg with Tab Ranitidine $150 \mathrm{mg}$ thrice a day. On day 4, temperature was measured $98^{\circ} \mathrm{f}$ and patients developed rashes on both hands and bilateral legs and planter surface of feet. On examination the rashes was peripheral distributing in body which was red erythematous nontender petechial over palmer surfaces of both hands (Figure 1).

The patechie were also started developed on planter surfaces of feet subsequently (Figure 2). Patient had complained of itching in the rashes as well all over the body. On day 5, Platelet count was within normal limits (Plt count-1.50lakh to 2.5lakh/cumm) and NS 1 antigen for dengue infection was negative. Antibiotics and other medication were stopped and he was prescribed Tab Cetirizine $10 \mathrm{mg}$ at night along with Calamine lotion for locally application. After stopping the antibiotics and other medication fever subsides turned back to normal body temperature $\left(98^{\circ} \mathrm{f}\right)$ and rashes and itching were start to disappear and took 3 days to complete remission.

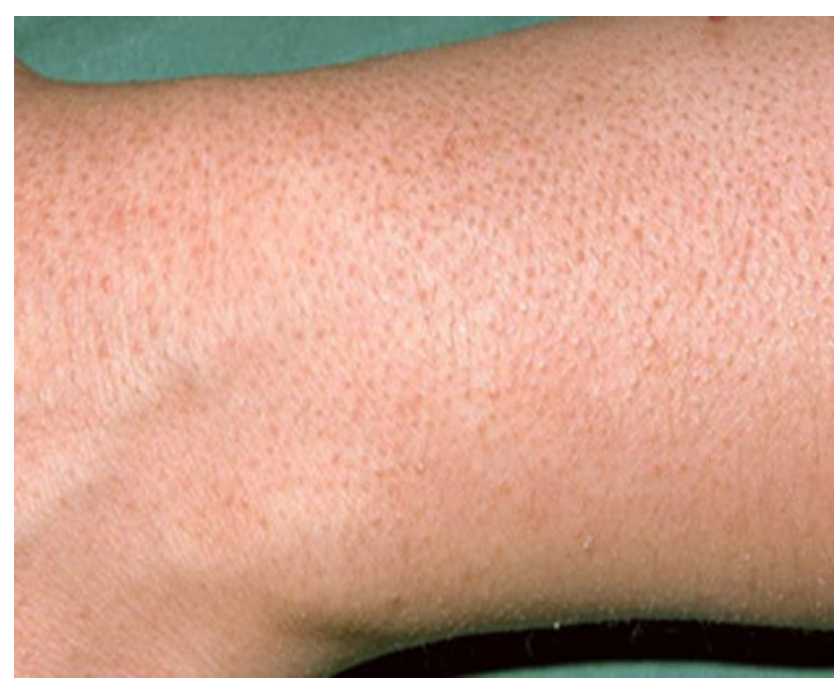

Figure 2: Clinical manifestation of petechial in the legs.

\section{DISCUSSION}

In our case, patient come to hospital with complain of fever and body ache for 3 days. Then he was worked up for cause of fever. He was prescribed a combination of antibiotics in fixed dose. This rashes is caused by many type drugs and is indicator of a variety of pathological process. $^{2}$ Cefixime, as a third generation cephalosporin, can be taken orally in the dose of $200 \mathrm{mg}$ and $400 \mathrm{mg} .{ }^{3}$ Currently, 3rd generation cephalosporin like cefixime, and ceftriaxone are used as broad spectrum, used to treat many of serious infections which are resistant to many other antibiotics used commonly. However, their use should be avoided in case of Enterobacter infections. ${ }^{4}$ Cefixime can produce a variety of hypersensitivity reactions. Common adverse events associated with cefixime include fever, skin rashes, anaphylaxis, 
granulocytopenia, haemolytic anaemia etc. ${ }^{5}$ Ofloxacin is a 2nd generation fluoroquinolone and is a racemic mixture of $50 \%$ Levofloxacin and 50\% dextrofloxacin. ${ }^{6}$ Fluoroquinolones block bacterial DNA synthesis by inhibiting bacterial topoisomerase II (DNA Gyrase) and Topoisomerase IV. It has a half-life (t1/2) of 5-7 hours with an oral bioavailability up to $95 \%$. Ofloxacin is administered for both gram negative and gram positive bacteria and is administered in a dose of $400 \mathrm{mg}$ once a day. It is available in $200 \mathrm{mg}$ and $400 \mathrm{mg}$ tablet form for oral use. Fluoroquinolones are effective in the treatment of urinary tract infection, bacterial diarrhoea and respiratory tract infection and are frequently employed for the same.

Ofloxacin is usually well tolerated with lesser serious adverse reactions. However a new warning label is requested by United state FDA in 2004 to be added to all the fluoroquinolones regarding, tendon damage, peripheral neuropathy QTc prolongation, epidermal necrolysis and Steven Johnson syndrome. ${ }^{7}$ Our patient was administered a fixed-dose combination of cefixime $250 \mathrm{mg}$ and ofloxacin $200 \mathrm{mg}$ for alleviation of her symptoms of fever with headache and body ache by a local physician. Many physicians use this drug these days as it provides a multi-pronged therapeutic approach to many infectious causes and has a relatively safe profile. The petechial rash which occurred in our patient can be attributed as a rare side effect of any of these two coadministered drugs. As it was a fixed-drug combination tablet and both the drugs have almost similar pharmacokinetics, one cannot clearly show which drug was the offending medication.

In order to prevent future episodes of such dermatological pathologies, our patient has been advised to cautious from the use of fluoroquinolones and cephalosporin's.
The patient was advised to store this information and to give the same to any physician who treats him.

Funding: No funding sources

Conflict of interest: None declared

Ethical approval: The study was approved by the Institutional Ethics Committee

\section{REFERENCES}

1. Fett NCJ, Ofori AO. Evaluation of adults with cutaneous lesions of vasculitis. www.uptodate.com.

2. Roujeau JC. Clinical heterogeneity of drug hypersensitivity. Toxicology. 2005;209(2):123-9.

3. Carruthers SHG, Brian BM. Morreli's Clinical Pharmacology Drug Therapy of Common Diseases: Problem-Based Therapeutic Decisions, $4^{\text {th }}$ edn.

4. Sanders CC. Beta-Lactamase stability and in vitro activity of oral cephalosporins against strains possessing well-characterized mechanisms of resistance. Antimicrobial agents and chemotherapy. 1989;33(8):1313-7.

5. Brunton LLCB, Knollmann BC. Goodman and Gilman's The Pharmacological Basis of Therapeutics, Penicillins, Cephalosporins and Other $\beta$-Lactam Antibiotics, $12^{\text {th }}$ edn; 2011.

6. Boopathy DPM, Mathew B. Method development and validation of simultaneous determination of Ofloxacin and Satranidazole in pharmaceutical dosage form by RP-HPLC. Der Pharmacia Letter. 2010;2(2):22-6.

7. Tanne JH. FDA adds "black box" warning label to fluoroquinolone antibiotics. Bmj 337:a816. 2008.

Cite this article as: Kumar S, Nirmal K, Kumar AN, Bhattacharya SK. Cefixime and Ofloxacin fixed dose combination induced petechial rash: a case report. Int J Basic Clin Pharmacol 2017;6:211-3. 